\title{
Review and Assessment of the Different Categories of Demand Response Potentials
}

\author{
Géremi Gilson Dranka ${ }^{\mathrm{a}, \mathrm{b}}$, Paula Ferreira ${ }^{\mathrm{c}}$ \\ ${ }^{a}$ ALGORITMI Research Center, University of Minho, Guimarães, Portugal, geremidranka@ gmail.com \\ ${ }^{b}$ Department of Electrical Engineering, Federal University of Technology, Paraná, Pato Branco, Brazil \\ ${ }^{c}$ ALGORITMI Research Center, University of Minho, Guimarães, Portugal, paulaf@dps.uminho.pt
}

\begin{abstract}
Demand Response (DR) is a well-known concept which has been recognized as an increasingly valuable tool to provide flexibility to the power system, to support the integration of Variable Renewable Energy (VRE) resources and to manage the grid more efficiently. In recent years, there have been a growing number of publications focusing on the estimation of different categories of Demand Response (DR) potentials (e.g. theoretical, technical, economic, and achievable) using different methodologies and assumptions in each research study. The contribution of the present study is twofold. Firstly, a literature review is undertaken focusing specifically on the categorization of the scientific approaches used to estimate the different categories of DR potentials. To the best of authors' knowledge, a general procedure for the estimation of each DR potential category is still missing. Therefore, a novel user-friendly and step-by-step theoretical framework for the determination of the different categories of DR potentials is presented. Findings of this study reveal that literature has extensively focused on the estimation of the technical DR potential followed by the economic, theoretical and achievable potentials respectively. A lack of understanding of the different categories of DR potentials was also identified, which sometimes have been unduly used in the literature. The proposed framework is supported on a small sample of numerical approaches and equations which results on a structured approach to bringing consensus to the DR potential assessment.
\end{abstract}

Keywords: Demand Response (DR), Demand-side Management (DSM), Load Flexibility, Categories of DR Potentials, Renewable Energy.

\begin{tabular}{|c|c|c|c|}
\hline \multicolumn{4}{|c|}{ Nomenclature } \\
\hline$E_{\text {year_com }}^{k}$ & Annual Electricity Consumption (commercial) & $P_{\text {max }_{-} \text {res }}^{k}$ & Maximum Installed Capacity (residential) \\
\hline$E_{\text {year_ind }}^{k}$ & Annual Electricity Consumption (industrial) & $n_{F L H}^{k}$ & Number of Full Load Hours \\
\hline$E_{\text {year_res }}^{k}$ & Annual Electricity Consumption (residential) & $N_{h_{-} \text {year }}$ & Number of Hours in a Year \\
\hline$s_{c o m}^{k}$ & Average Demand Share (commercial) & $n_{\text {house }}$ & Number of Households \\
\hline$s_{u t i l}^{k}$ & Capacity Utilization Level & $F D^{k}$ & Percentage of Flexible Demand \\
\hline$E_{c o m}^{k}$ & Commercial Sector Demand & $A_{\text {year }}^{k}$ & Production Capacity \\
\hline$E_{\text {hourly }}^{k}$ & Hour Electricity Demand & $f_{\text {rev }}^{k}$ & Revision Outages \\
\hline$E_{\text {hourly }(i)}^{k}$ & Hourly Theoretical DR Potential & $P_{\text {unit }}^{k}$ & Specific Capacity of Each Appliance \\
\hline$f_{e q}^{k}$ & Market Penetration of Each Appliance & $E_{\text {spec }}^{k}$ & Specific Electricity Consumption \\
\hline$P_{\text {max }_{-} \text {com }}^{k}$ & Maximum Installed Capacity (commercial) & $E_{\text {unit }}^{k}$ & $\begin{array}{l}\text { Specific Electricity Consumption of Each } \\
\text { Appliance }\end{array}$ \\
\hline$P_{\text {max_ind }}^{k}$ & Maximum Installed Capacity (industrial) & $D_{\text {profile }}^{k}$ & Typical Load Profile \\
\hline
\end{tabular}

\section{Introduction}

The enhancement of the flexibility in grid operations due to the high penetration of Renewable Energy Sources (RES) in power systems, with great unpredictability and variability characteristic, will be essential in the near future in order to accommodate the intermittent power output, primarily from wind and solar generation systems [1]. There are several possible sources of flexibility for the power system as pointed out by [2] such as wind and solar power generation ratio, flexible generation, network grid expansion, the excess of capacity, curtailment and also the use of Demand-Side Management (DSM) strategies. In order to meet the future electricity demand, public policy-makers should also ensure that supply would be sufficient to satisfy both the energy and the capacity over a forecast planning period [3]. However, only the supply-side resources are used in the Traditional Resource Strategic Planning (TRSP) [4]. On the other hand, for the Integrated Resource Strategic Planning (IRSP) the DSM strategies and other resources are supposed to be considered 
in the planning model [4]. The integration of large share of variable renewable energy into the energy system requires an integrated energy planning approach since it may increasingly affect the voltage and frequency control of the power systems and therefore the stability and reliability analyses may strongly contribute to addressing these concerns [5].

DSM strategies may be considered as "the practice of shaping the demand patterns and energy use [3]" in order to address supply shortages, interconnection's maximum capacity, control the load growth [6], optimize resource allocation [7] or even to mitigate environmental impacts [8] associated with energy production and intensive energy use. According to [8], "the implementing of managerial measures to produce the resources on the demand-side by influencing the load demand" can be defined as DSM which can be broadly divided into Energy Efficiency Measures (EEM) and Demand Response (DR) strategies. EEM might be roughly considered as permanent load reductions whereas DR is focused on load flexibility [9]. Consequently, DR strategies can be broadly classified as temporary load reductions (e.g. load shedding or load shifting) [10]. DSM strategies have been developing over time to deal with the economic and environmental challenges brought by the expansion of supply-side energy resources [11]. The main goals of DSM techniques are valley filling, load shifting, peak clipping, strategic load growth and strategic conservation [12]. Load shifting and valley filling strategies clearly can improve the grid load factor and avoid capacity costs, for example [4]. Ref. [11] argue that the integration between these two dissimilar strategies, i.e., the Supply Side Management (SSM) and DSM is essential to achieve a more accurate model for power system planning purposes. Investments in DSM strategies would avoid investments in the supply-side and also in new transmission grids [4]. According to [3], for the most part of power systems, it is more cost-effective to invest in DSM strategies than in the supply-side.

Furthermore, the increasing penetration of power generation from intermittent RES [13] (i.e. with limited controllability and predictability [14]), especially from wind and solar power [15], led to the development of intermittency mitigation techniques such as the specific use of DR strategies [16]. DR aims primarily to encourage end-users to reduce electricity usage by certain incentive schemes, especially when electricity prices are high [17]. According to the U.S. Department of Energy, DR can be defined as "changes in electric usage by end-use customers from their normal consumption patterns in response to changes in the price of electricity over time, or to incentive payments designed to induce lower electricity use at times of high wholesale market prices or when system reliability is jeopardized". DR programs can be divided into two main types (i) Incentive-based programs and (ii) Price-based programs [18]. There are also controllable DR programs in which the consumer accepts load curtailment promoted by an external entity under specific conditions [19]. DR programs are getting popular among utilities to match generation and demand in a more effective way [20] and it has a huge potential to improve the reliability of power systems [21]. International Energy Agency (IEA) highlights the fundamental contribution of DR measures for the integration of VRE and also projected that by 2040 nearly $185 \mathrm{GW}$ of flexible demand would be reached in a cost-effective way [22].

Traditionally, the balance between supply and demand has been achieved focusing on the supply side, mainly through the building or upgrading of new power plants, transmission and distribution systems [3]. It is worth mentioning that, from the power system's perspective, a reduction in demand has the same effect as an increase in supply. In this context, as reported by [23], the deployment of DR programs has been seen as an alternative to generation and transmission expansion. Beyond the high capability of reducing the peak load on the power system [24], DR might be used to contribute to power system regulation capacity in order to promote the wind power integration, for example [17]. Peak-demand reductions might result in deferring or avoiding new generation capacities and/or new transmission and distribution systems, in addition to other benefits such as possible reductions in production costs, the need of lower reserve margin capacity, increase of the security of supply [25] as well as lower transmission system utilization [24]. This last aspect is particularly important for power systems in which the transmission congestion problem is even more critical than the generation capacity. For this case, the use of DR strategies would reduce the load requirements primarily during peak times and therefore improving the transmission constraints [26]. DR might also provide some power system services more reliable than conventional generation systems such as spinning reserve [27] and peak load shaving [28]. DR may also help to integrate higher shares of intermittent renewables [29] by shifting and shaping electricity demand in a more costeffective way compared to traditional options [30]. Therefore, the implementation of DR strategies might reduce customers' utility bills such as verified in [31], and improve the resource-efficiency of electricity generation in addition to the promotion of social and environmental benefits [24]. Thus, regardless of all the benefits related to the development of smart grids [32], DR is expected to become a valuable energy solution [17], being able to mitigate the variability of RES [33]. The fast DR deployment together with little additional infrastructure is likely to be the most relevant advantages regarding the use of this source of flexibility [34].

Consequently, the sustainable and affordable energy transition requires action on the demand-side in addition to the supply-side. However, although DR may offer a set of advantages [18], many barriers [35] still stand for its effective deployment and implementation mostly because of its highly diverse and multifaceted nature. Therefore, it requires research in a wholly holistic context in order to surpass these previously mentioned barriers. For this reason, it is certainly required a diversity of approaches and methodologies to address the different faces of this complex problem which englobes different sectors and applications. A systematic literature review of DSM strategies is addressed by [8] in which the authors proposed a novel theoretical framework in order to unify the methodologies, terminologies and concepts associated with DSM in the literature. Most of the previous reviews have been traditionally focused on specific sectors or power systems and with a particular focus on the qualitative analysis of DR issues, exploring the benefits and challenges of current DR schemes. The number of publications that investigate aspects of the potential of flexible loads has been also steadily growing in the last years [36]. Particularly, there have been a growing number of studies focusing on the 
estimation of different categories of DR potentials (e.g. theoretical, technical, economic, and achievable) using different assumptions in each research study. However, limited attention has been given to both (1) A review of the different categories of DR potentials and (2) A general methodological procedure to assess each category of DR potential. Despite the large amount of research on the topic and to the best of authors knowledge, a general procedure for the estimation of the different categories of DR potentials is still missing.

Based on this context, the following research questions remain partially unanswered by the available literature. 1) How to assess the potential of flexible demand (DR potential) across different sectors? and 2) How can each DR potential category be distinguished? Therefore, a more comprehensive analysis is necessary for the topic and the answers to these questions are fundamental to determine not only which are the most relevant factors and parameters to determining each DR category potential but also to evaluate the extent to which these potentials contribute to the transition to a decarbonized energy system. Therefore, this paper aims to be twofold in order to contribute to filling these research gaps. Firstly, a literature review is undertaken focusing specifically on the different categories of DR potentials previously mentioned. Secondly, a user-friendly step-by-step procedure is proposed in order to facilitate the future estimation of DR potentials.

The overall structure of this paper is divided into seven main sections and proceeds as follows. This first section contextualizes the research by providing background information on the subject. Section 2 presents the methodological approach of the research and Section 3 provides a theoretical background on DR programs. A review on the categories of DR potentials is further proposed (Section 4). Then the new conceptual framework is presented in Section 5 which represents an outcome of the literature review. Section 6 attempts to discuss the findings which emerged from the literature review. Finally, Section 7 draws together the key findings including its main implications for future research.

\section{Methodological Approach}

This work will follow a qualitative data collection technique approach within the research design. The research nature of this study may be termed as an exploratory study [37]. A qualitative study is conducted using the inductive approach in order to generate theoretical concepts. The different categories of DR potentials are assessed based on an in-depth systematic literature review analysis. The systematic literature review conducted in this research has as its main objective to synthesize a body of evidence of the most recent relevant and significant research and to provide a full overview of the current topic in a repeatable, comprehensive and systematic way [38]. Ref. [39] defines a systematic review as " $a$ formalized method for synthesizing a body of evidence in a reliable manner that aims to maximize transparency, comprehensiveness and objectivity”.

A four-step process is considered in this research for conducting the systematic review process following the procedure proposed in [37]. Firstly, the formulation of the research questions was established based on the research gap found by the authors. Subsequent to this, a list of potentially relevant research studies using online databases were undertaken in order to generate a list of the most comprehensive research in the field. The key-word searches used as the selection criteria were performed to locate peer-reviewed journals and it was included the following search terms: (a) Theoretical, (b) Technical, (c) Economic, (d) Achievable, (e) Practical, (f) Social (g) Market and (h) Realizable, combined with the terms (i) Demand Response Potential, (j) Demand-side Flexibility, (k) Flexible Demand Potential, (l) Flexible Load Potential, (m) Load Flexibility Potential, (n) Potential of Load Reduction and (o) Load Management. Then, a screening process (by title and abstract) was conducted in the phase of selection and evaluation, excluding the research papers which were not relevant regarding the previously defined research questions [40]. The analysis and synthesis of the results were undertaken breaking down each study in the year of publication, potential DR category, sectoral coverage, spatial resolution and special notes. Finally, a discussion section regarding the main findings was undertaken and a novel comprehensive framework was proposed as a result of this review analysis. Therefore, the methodology was basically divided into the research question(s) formulation, identification, screening process and analysis and synthesis of the results for the included papers as illustrated in Fig. 1. The novel conceptual framework for the estimation of the DR potentials is proposed in a user-friendly manner in order to provide sufficient methodological detail to allow replication. 


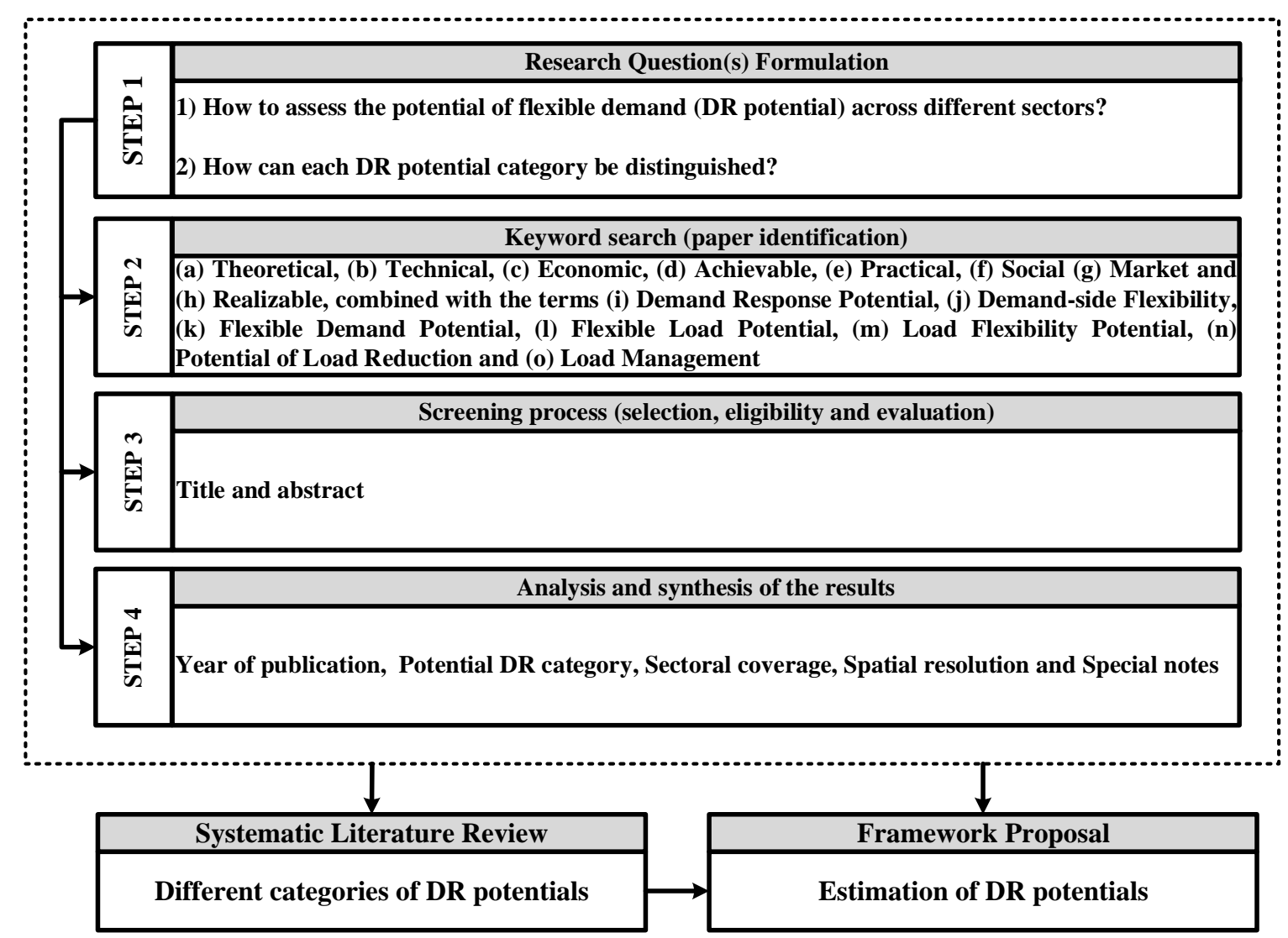

Fig. 1. Methodological approach considered for conducting the systematic review process.

\section{Theoretical Background on Demand Response Programs}

Literature review about DR has been extensively performed along with the last years addressing different aspects of the field [41]. In [42] the authors selected 117 papers which addressed different DR issues and concluded that "all major aspects of DR are relatively well covered by model developments (DR pricing schemes, the impact of DR on electricity systems and markets and the participation of selected end-uses in DR schemes)". Aspects regarding the different market mechanisms (i.e. incentive-based or price-based DR mechanisms) have been also addressed by a great number of works such as in [43] and [44]. Time-sensitive pricing can be classified as non-dispatchable resources [45] and are traditionally split up into Time-Of-Use (TOU), Critical Peak Pricing (CPP), Real Time Pricing (RTP) and Peak Time Rebate (PTR) [46]. For dispatchable resources, the decision to dispatch can be broadly divided into reliability (capacity, reserve, energy or regulation) and economic (demand bidding \& buy-back) categories.

In [47], the authors categorized the flexibility requirements of VRE systems into technical, economic, and market potentials with a focus on Europe and particularly addressing the case of the German power system. Studies comparing specifically the technical with the economic DR potential can be found in [48] for example. The literature review presented in [47] attempted to address the following topics: flexibility requirements, resource potential in future energy systems and storage demand. The authors of [49] investigated the DR flexibility potential on office buildings and it has been reported that the estimation of DR potentials may be further restricted by the variation of thermal comfort performance within the buildings. A literature review regarding the different methodologies used to assess the potential for flexible use in buildings energy systems is presented by [50]. Further, the assessment of buildings flexibility potential was addressed by [51]. To better understand the mechanisms of different DR programs, Ref. [36] classified the different DR programs in the U.S. electricity markets. Ref. [52] evaluated the economic load management potential with a particular focus on specific buildings of the industrial and commercial sectors (e.g. offices and schools) for the state of Texas in the U.S. A methodology to evaluate the load-shifting potential in Small- and medium-sized enterprises (SMEs) is assessed in [53] based on a case-study of four companies in Germany. The authors of [54] focused on the DR potential (technical and economic in this case) review analysis of the power-to-heat $(\mathrm{PtH})$ technologies within the European energy system.

Fig. 2 presents a brief overview of different DSM programs [55]. DSM options might be valuable according to different timescales as illustrated in Fig. 2. As stated previously, energy efficiency measures are not dispatchable resources and energy efficiency can be considered a demand-side resource, which provides permanent demand reductions. Energy efficiency is usually valued during the energy system planning process and its impacts are mostly related to the long-term horizon [56]. Price-based programs use time-varying electricity rates (i.e. TOU, CPP and RTP). For this type (i.e. pricebased programs), when the electricity prices are high, customers are intended to reduce their electricity consumption. For incentive-based programs, however, customers receive money from the utility to reduce their loads at requested times (e.g. when electricity prices are high or due to reliability problems). Detailed information about Fig. 2 can be found in [56]. 


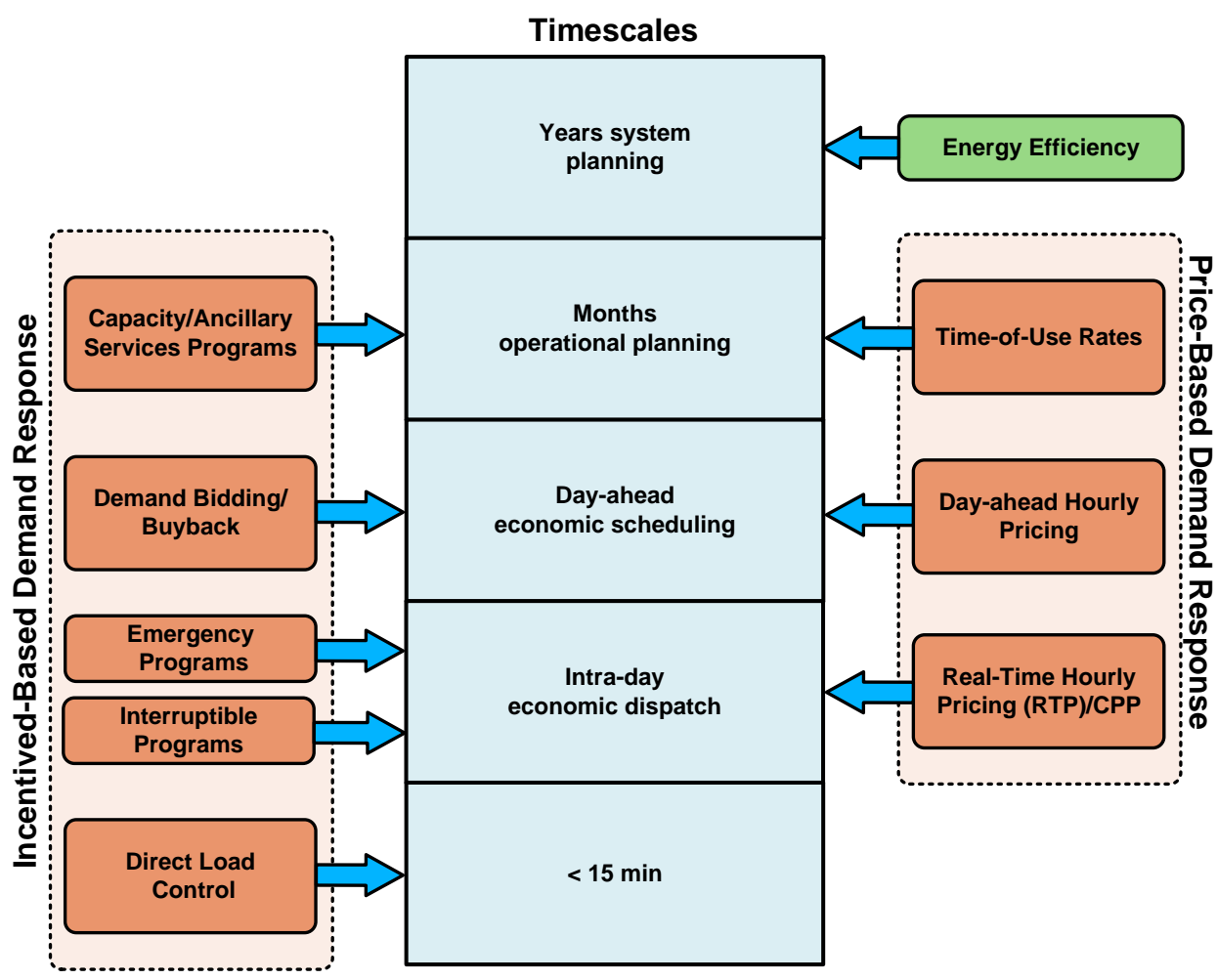

Fig. 2. Role of DSM in Electric System Planning and Operations.

Source: Adapted from [56].

Existing literature usually distinguishes the different categories of DR potentials as Theoretical, Technical, Economic and Achievable. A simplified classification is considered by Ref. [57], which broadly divides the DR potentials into only three categories: technical, economic and achievable. Ref. [58] also consider the same classification of Ref. [57]. In this last case, however, the achievable potential is divided into the Maximum Achievable Potential (MAP) and the Realistic Achievable Potential (RAP). The attitudinal (e.g. consumers' resistance), societal and market barriers which limit the customer participation are taken into account for the MAP definition. The RAP discounts MAP, considering additional constraints related to impediments to DR implementation (e.g. regulatory, political and financial barriers) [58]. Table 1 presents a diverse number of classifications regarding the different categories of DR potentials.

Table 1: Possible DR Classifications Used Along with the Literature.

\begin{tabular}{ccl}
\hline Reference & Year & \multicolumn{1}{c}{ DR Categories } \\
\hline$[58]$ & 2009 & Technical, Economic and Achievable (MAP and RAP) \\
{$[57]$} & 2010 & Technical, Economic and Achievable \\
{$[25]$} & 2010 & Technical, Economic and Realizable \\
{$[59]$} & 2011 & Theoretical, Technical, Economic and Achievable (or Market) \\
{$[60]$} & 2015 & Theoretical, Technical, Economic, Practical and Social \\
{$[61]$} & 2015 & Technical and Market (also referred to as Achievable) \\
{$[53]$} & 2017 & Theoretical, Technical, Economic, Acceptable and Realizable \\
{$[62]$} & 2017 & Technical, Economic and Achievable \\
{$[63]$} & 2018 & Theoretical, Technical, Economic and Realizable \\
{$[64]$} & 2018 & Theoretical, Technical, Economic and Practical \\
\hline
\end{tabular}

Significant differences can be identified when distinguishing the so-called "achievable" DR potential, which has been treated in different ways within the literature. Some authors split this last concept (i.e. achievable DR potential) into two: MAP and RAP [58], Acceptable and Realizable [53] or even Practical ${ }^{1}$ and Social [44]. Other authors do not split the "achievable" DR potential but refer to it with different nomenclatures such as practical [64], realizable [25], feasible [53] or even Market [59] DR potential. Therefore, these terms have been used interchangeably across different research papers within literature. In fact, for all cases, the "Achievable" [59] (or "Practical" [60], "Social"[60], "Realizable" [25], "Feasible" [53] or even "Market" [59]) DR potential would represent a set of one or more barriers to the DR implementation [25] such as summarized in the proposed framework illustrated in Fig. 5 (Section 5). This might suggest the need to standardize this term definition in order to avoid the undue use of these words. Similarly, this would

\footnotetext{
${ }^{1}$ For the authors of [60], the practical DR potential corresponds to the intersection between the economic and social potential.
} 
simultaneously contribute to overcoming the above-mentioned barriers, by making easier future reviewing pathways, for example.

Therefore, after a systematic literature review, the different classifications regarding the categories of DR potentials were unified in a standard classification as illustrated in Fig. 3. The different categories of DR potentials versus capacity $(\mathrm{GW})$ together with a brief description of each potential are illustrated in Fig. 4. Along with this paper, for the sake of clarity, the term that will be most used to describe this last DR potential is "Achievable".

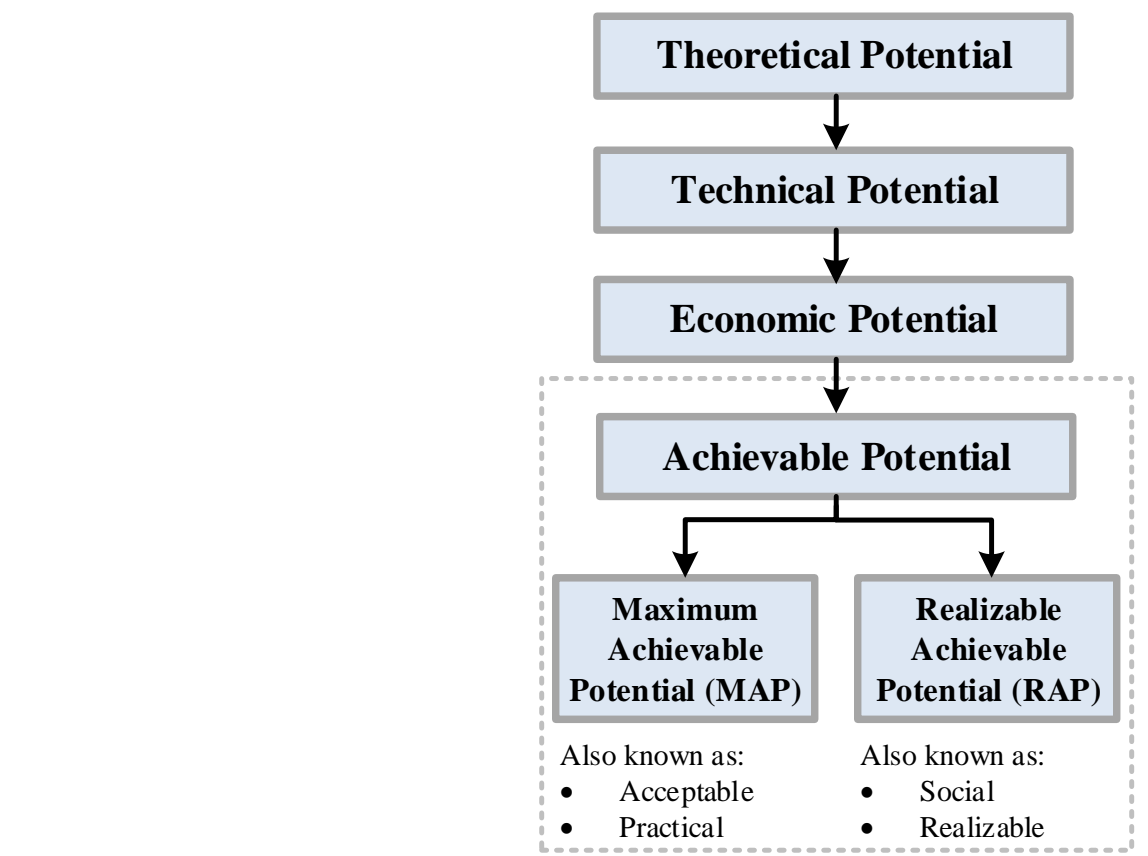

Fig. 3. Overview of the main categories of DR potentials.

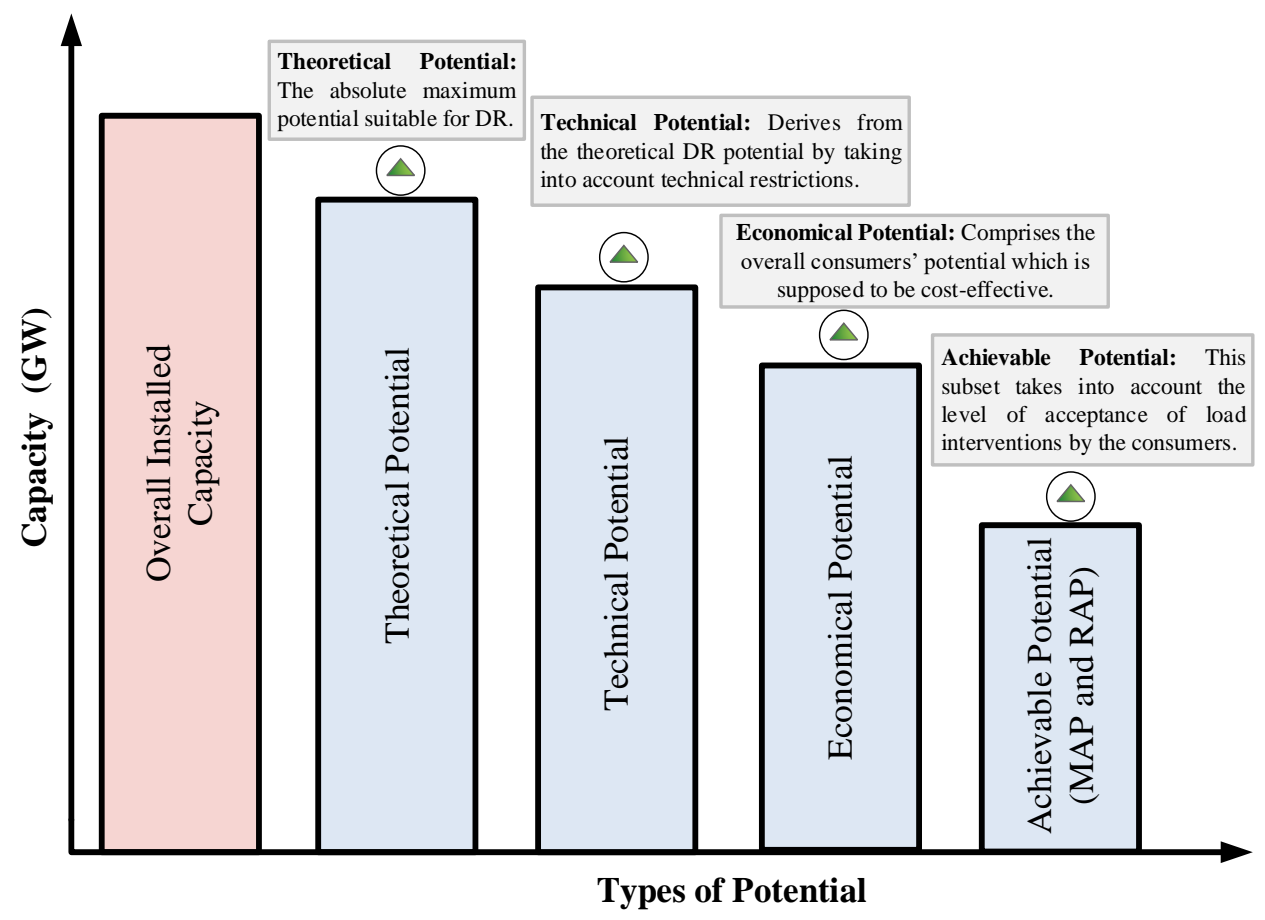


that offers contradictory definitions for the 'Technical DR Potential' concept. Ref. [10], for example, highlights that "the technical potential includes only those [equipment] that can be controlled by the existing information and communication infrastructure". In contrast to [10], Ref. [65] defines that "the technical potential is the amount of the load that is temporally available for load shifts when taking into account technical peculiarities and legal regulations". In agreement with [65], Ref. [63] argues that "the technical potential is generally smaller than the theoretical potential, as it takes technical restrictions, such as the number and duration of interventions into account".

Therefore, while a variety of definitions for the 'Technical DR Potential' have been suggested, this paper will use a similar term definition as suggested by Ref. [63] which is also considered in the evaluation of the technical DR potential ${ }^{2}$ of [48] and [66]. A general list of definitions derived from the literature review is presented in

Table 2 aiming to propose standard definitions for each category of DR potential.

Table 2: Definitions of each DR potential.

\begin{tabular}{|c|l|l|}
\hline $\begin{array}{c}\text { DR } \\
\text { Potential }\end{array}$ & Definition \\
\hline Theoretical & $\begin{array}{l}\text { The theoretical DR potential comprises the overall (i.e. all facilities and devices) consumers' potential suitable for } \\
\text { DR. }\end{array}$ & [10,63] \\
\hline Technical & $\begin{array}{l}\text { The technical DR potential derives from the theoretical DR potential by taking into account technical restrictions (e.g., } \\
\text { the shifting time, duration and number of interventions). }\end{array}$ & [63] \\
\hline Economic & $\begin{array}{l}\text { The economic DR potential derives from the technical potential when the costs for implementing DR (e.g. investments } \\
\text { and operational) are taken into account. Therefore, it comprises the overall consumers' potential which is supposed to } \\
\text { be cost-effectiveness. }\end{array}$ & $\begin{array}{c}\text { [25,59,63] } \\
\text { (1) Maximum Achievable Potential (MAP): The MAP is restricted by the attitudinal (e.g. consumers' } \\
\text { resistance), societal and market barriers which limit customer participation in DR programs. For this case, } \\
\text { it is presumed that no impediments for the effective implementation of DR measures would occur. } \\
\text { Achievable } \\
\text { (2) } \begin{array}{l}\text { Realizable Achievable Potential (RAP): The RAP is derived from the MAP by considering other } \\
\text { impediments to DR program implementation (e.g. regulatory, political and financial barriers) which in turn } \\
\text { would limit the savings from DR programs. }\end{array}\end{array}$ \\
[58]
\end{tabular}

\section{A Review on the Categories of DR Potentials}

A set of recommendations to incorporate DR into resource planning models is proposed by [24]. Due to a set of barriers such as legal, policy, economic and societal, the DR implementation is restricted only to selected markets and the traditional DR programmes mostly focus on large industrial loads [10]. Therefore, literature has mostly focused on the assessment of DR potential in large-scale and energy-intensive industries [64]. However, a great number of works [6769] have been recently addressed the assessment of residential and commercial DR potentials as promising sectors that would contribute to the power system flexibility [10]. Country-specific analysis of DR potential has been extensively addressed in literature such as in [63] and [70] for the specific case of Germany and in [71] for Denmark .

DR assessments have been traditionally considered using qualitative approach analysis [70]. The evaluation of DR potential as a quantifiable resource, however, has been assessed only by a few works in the available literature such as in [70] and the precise quantification of the load flexibility potential is considered a complex task [47]. In [70], for instance, the authors highlight that the major benefit of employing DR is the reduction of the peak power system capacity, which represented about $10 \mathrm{GW}$ for the power system evaluated (12\% of peak load). For the power system analyzed in [70] the contribution of DR on the integration of variable renewable electricity power generation is found to be not significant.

A great number of studies have estimated the potential of DR resources across different sectors (i.e. industrial, commercial and residential) at varying scales (e.g. local, regional, national and even across continental regions) [61]. An up-to-date review analysis is undertaken by [20] which concluded that "existing DR programs around the world demonstrated a highly asymmetrical development between different regions". Ref. [41] highlights the need for the development of novel DR modeling approaches which would be able to incorporate as many applications as possible and that consider the interactions of DR with other system resources. Ref. [72] specifically review the DR in the residential sector including the latest ICT developments. The authors of [28] conducted an extensive literature review regarding DR programs and also proposed a communication and computation-based DR program for the residential sector. The longterm impact of DR measures in the industrial, residential and tertiary sectors is assessed in [73] for the Portuguese electricity system using the OSEMOSYS software tool. The authors of [73] concluded that the implementation of DR measures would decrease both the overall system capacity (reaching up to $2.2 \%$ comparatively to the BAU scenario) and the total system costs (decreasing up to 2.23\%) and would increase the share of renewable energy in the Portuguese power system. However, Ref. [73] highlight the need to further assess the costs to implement such DR measures since it was not considered in their assessment. The study of [74] investigated the role of sector coupling in the Brazilian power sector. A deterministic linear optimization model was considered in this last paper [74] and a simplified model for the DR representation was used, considering only part of the commercial and industrial sectors as potential flexible loads. The duration of load interventions is not considered in the modeling approach proposed by [74]. The authors [74] concluded

\footnotetext{
${ }^{2}$ The authors of these papers do not mention directly the definition of 'Technical Potential' as proposed by [63]. However, we have inferred it because of the assumptions made by those papers to establish their DR potential.
} 
that for the specific case of Brazil, the DR contribution is limited to load balancing (reaching up only to $0.04 \%$ of the total annual electricity demand) and this can be mostly explained because of its high renewable potential. On the other hand, peak load reductions of about 3.3 GW are projected due to the DR implementation for the power system evaluated in [74].

A number of recent studies such as [27] and [41] addressed the key barriers and the challenges to the deployment of DR. Ref. [41] concluded that DR contributes only to a limited extent in the current electricity market and for this reason, most of its potential benefits cannot be fully exploited. Ref. [75] considered in their modeling approach that consumers will have a more active behavior in the future and they will give more importance to quality and sustainability aspects. In fact, technology advancements on the demand-side have contributed to an increasingly active behavior of consumers [76]. The growing market share of smart appliances brought about by the evolution of smart grids may strongly facilitate the insertion of demand-side resources such as air conditioning, washing machines and refrigerators without compromising user comfort. Ref. [75] presented proposals for public, regulatory, and business strategy policies to be implemented by the Brazilian government in the 2030s. In [17] the authors proposed a coordinated optimization model for the generation and transmission expansion problem considering the inclusion of DR into the optimization problem. The authors of [77] presented a method to assess the so-called realizable DR potential for ancillary services purposes.

Based on this background, Table 3 gives a general overview regarding the systematic literature review undertaken by this research paper concerning the different DR potentials addressed along with previous research. The papers were selected considering those works which (1) explicitly refer to the category of DR potential assessed or (2) the category of DR potential assessed could be indirectly retrieved. Further, a set of assumptions are reconsidered in order to shape the addressed DR potentials with the standard definitions proposed by the authors of this review paper.

Table 3: Overview of each potential DR category.

\begin{tabular}{|c|c|c|c|c|}
\hline Reference & Year & Potential DR Category & Sectoral Coverage & Spatial Resolution \\
\hline [78] & 2009 & Technical/Economic & Commercial & Local Consumer \\
\hline [58] & 2009 & Achievable (MAP and RAP) & Industrial, Commercial and Residential & National (U.S.) \\
\hline [79] & 2010 & Achievable (RAP) & Industrial, Commercial and Residential & Regional (Midwest ISO region) \\
\hline [25] & 2010 & Technical/Economic & Industrial, Commercial and Residential & National (Germany) \\
\hline [48] & 2011 & Technical/Economic & Industrial $^{\text {a }}$ & National (Germany) \\
\hline [59] & 2011 & Theoretical, Economic and Achievable & Refrigeration systems $^{\mathrm{b}}$ & National (Germany) \\
\hline [80] & 2012 & Technical and Economic & Industrial, Commercial and Residential & Regional (Eastern Interconnection - U.S.) \\
\hline [81] & 2013 & Theoretical & Commercial & Commercial Building \\
\hline [10] & 2014 & Theoretical $\rightarrow$ Technical & Industrial, Commercial and Residential & 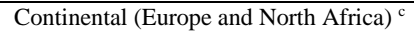 \\
\hline [71] & 2014 & Technical & Industrial, Commercial and Residential & National (Denmark) \\
\hline [82] & 2014 & Technical & Residential & National (Denmark) \\
\hline [83] & 2014 & Technical & Residential & Local (Kainuu) ${ }^{d}$ \\
\hline [84] & 2015 & Theoretical $^{\mathrm{e}}$ & Industrial, Commercial and Residential & Continental (Europe - 34 countries) \\
\hline [85] & 2015 & Theoretical $^{f}$ & Residential $^{\mathrm{g}}$ & National (Belgium) \\
\hline [86] & 2015 & Technical and Economic ${ }^{\mathrm{h}}$ & Residential and Commercial & National (Germany) \\
\hline [61] & 2015 & Market $\rightarrow$ Achievable $^{\mathrm{i}}$ & Industrial, Commercial and Residential & Regional (Shangai - China) \\
\hline [70] & 2016 & ${\text { Economic } / \text { Social } \rightarrow \text { Achievable }^{j}}$ & Industrial, Commercial and Residential & National (Germany) \\
\hline [66] & 2016 & Technical/Economic & Industrial, Commercial and Residential & Continental (West-European) \\
\hline [87] & 2016 & Theoretical & Industrial and Residential ${ }^{\mathrm{k}}$ & Continental (Europe) \\
\hline [67] & 2017 & Social $\rightarrow$ Achievable $^{1}$ & Residential and Commercial & National (Germany) \\
\hline [53] & 2017 & Technical & Commercial & Company (Germany) \\
\hline [88] & 2018 & Theoretical & Industrial, Commercial and Residential & Northern European Countries \\
\hline [89] & 2018 & Achievable & Residential & National (Germany) \\
\hline [68] & 2018 & Technical & Residential and Service & National (Finland) \\
\hline [63] & 2018 & Technical & Industrial, Commercial and Residential & National (Germany) \\
\hline [90] & 2018 & Technical & Plug-in electric vehicles & National (Germany) \\
\hline [52] & 2018 & Economic & Industry and Commercial & Local (Texas) \\
\hline [69] & 2018 & Technical and Economic & Industrial, Commercial and Residential $^{\mathrm{m}}$ & National (Nigeria) \\
\hline [73] & 2018 & Theoretical/Technical $^{\mathrm{n}}$ & Industrial, Commercial and Residential & National (Portugal) \\
\hline [62] & 2018 & Technical, Economic and Achievable & Industrial, Commercial and Residential & Regional (Michigan) \\
\hline
\end{tabular}

${ }^{\mathrm{a}}$ The focus was on energy-intensive industries.

${ }^{\mathrm{b}}$ The load management potential is evaluated with a particular focus on refrigeration systems considering the potential for each sector that uses this cross-sectional technology. The base data for the city of Mannheim is used and further extrapolated to the national power system of Germany.

${ }^{\mathrm{c}}$ The analyses were undertaken for 30 countries (Europe and North Africa). However, for North African countries only energy-intensive industries were considered due to the scarcity of data. Although the authors mention that the theoretical DR potential is assessed, a set of technical restrictions are also considered by the authors. Therefore, following the definitions proposed along with this work, the DR potential assessed in [10] should be interpreted as the 'Technical Potential'

${ }^{\mathrm{d}}$ The focus of this work was in the residential sector with metered data collected from 1630 households from Kainuu (Finland).

${ }^{\mathrm{e}}$ For inference (because the authors do not mention which DR potential is analyzed).

${ }^{\mathrm{f}}$ The authors also mention that this potential may be underestimated since the results were extrapolated based on a pilot program. 
${ }^{\mathrm{g}}$ Here, the flexible potential of five household smart appliances was evaluated based on a set of measurements.

${ }^{\mathrm{h}}$ The authors mention that "the results determined a practical shifting potential". However, following the definitions used along with this work and the results presented in the paper [86], this definition should be interpreted as the 'Economic Potential'.

${ }^{i}$ Following the definitions used along with this work, the "Market" DR potential cited in the paper would correspond to the "Achievable" DR potential.

${ }^{\mathrm{j}}$ The author mention that " a model-based assessment of the economic DR potential in Germany is presented". Further, the author refers to the estimation of an "approximated social potential".

${ }^{\mathrm{k}}$ The following sectors were considered by the authors: industrial, cooling, households, heat pumps and e-mobility.

${ }^{1}$ Following the definitions used along with this work and the results presented in the paper [67] this definition should be interpreted as the achievable potential.

${ }^{\mathrm{m}}$ The DSM potential is assessed considering different levels of industrialization.

${ }^{n}$ The authors mention that "the theoretical potential of DR is computed". However, they also consider a set of technical restrictions in the model formulation. Therefore, following the definitions used along with this work, the definition that would be considered here is precisely the 'Technical Potential'.

The following subsections will particularly focus on a review analysis regarding the different DR potentials illustrated in Fig. 3.

\subsection{Theoretical DR Potential}

Ref. [59] addressed the potential for load management in Germany with a particular focus on the refrigeration systems across different sectors (i.e. industrial, commercial and residential). The authors of [59] addressed the theoretical (4.2 $\mathrm{GW})$, economic $(3.2 \mathrm{GW})$ and achievable $(2.8 \mathrm{GW})$ DR potential. The achievable potential corresponds to $66 \%$ of the theoretical potential for the power system evaluated in [59].

Ref. [88] estimated the theoretical DR potential across different sectors for seven Northern European countries (Denmark, Norway, Sweden, Finland, Lithuania, Estonia and Latvia) as 12-23 GW considering a peak load of about 77 GW.

The total theoretical DR potential for Europe (34 countries) was assessed by [84], estimating a total of $800 \mathrm{TWh}$ for suitable DR processes across industrial, commercial and residential sectors. This represents a value slightly higher than $52 \mathrm{GW}(9.4 \%$ of peak load) split into residential (42\%), industrial (31\%) and commercial (27\%) sectors. The authors of [84] concluded that the share of flexible loads for the industrial sector is higher for countries with higher shares of industrial electricity consumption such as Sweden and Norway, for example [84].

\subsection{Technical DR Potential}

The technical DR potential is addressed in [86] for the German power system (specifically for the residential and commercial sectors) which reach up to $8 \mathrm{GW}$ by 2030. Ref. [86] also conducted an economic analysis for the residential sector and concluded that the income generated by load management is not enough to cover the investment in Information and Communications Technology (ICT) and therefore the DR was proved not to be cost effective.

The technical DR potential of flexible demand for the Danish power system is assessed in [71] across industrial, commercial and residential sectors using two approaches. Firstly, a bottom-up approach is considered to assess the flexible load potential for each sector (i.e. industrial, commercial and residential) for a 100\% RES in 2050. Then, the EnergyPLAN software is applied to perform the simulations in order to identify the most adequate levels of the flexible loads for the power system assessed. It is worth mentioning that the software EnergyPLAN has been extensively used to the simulation of future energy scenarios focusing on the large-scale integration of RES into the power system [91] and recently it has been also used to the inclusion of DR into the long-term simulations as addressed by [71].

\subsection{Economic DR Potential}

The economic DR Potential (also referred to as Techno-Economic DR Potential [59]) derives from the technical DR potential. In this case, however, the costs to activate this technical potential should be taken into account. According to [59], "the economic potential describes the cost-effective application of load management". The overall costs comprise both the investments and operational costs [25]. Traditionally, the DR potential that is considered cost-effective would technically suggest that the overall costs of implementing such DR measures are lower than the cost of energy supply. The incremental cost of electricity from peaking generators and the use of both cost and risk combination of portfolios with and without DR (i.e. portfolio analysis of DR) are other examples of how literature has been evaluated the costeffectiveness of DR strategies [62].

The potential of technical and economic DR potential for wind integration is assessed by [25]. The authors of [66] identified the least-cost options for West-European countries for the year 2050 through the assessment of five options which included flexibility potential of DR strategies. This last paper assessed the economic DR potential and considered the costs for load shifting ranging from 2 to $100 € / \mathrm{kW}$ and the costs for load shedding varying between 200 and 5000 $€ / \mathrm{MWh}$, depending on the process assessed. For the power system evaluated in [66], the total system costs can be reduced up to 3\% by the implementation of the DR measures. Ref. [41] point out that currently one of the most fundamental questions regards about how DR should be priced in terms of investment and operational costs. These cost aspects remain still unclear and should receive attention in future works. 


\subsection{Achievable DR Potential}

This subset takes into account the level of acceptance of load interventions by the consumers. Few published studies have attempted to evaluate the achievable DR potential. Most of the studies which attempted to assess the achievable DR potential have been limited to convenience samples and in general, it has been restricted to the analysis of small regions such as in [61] and [62]. In [59], for example, the achievable potential was estimated specifically for the refrigeration sector in Germany. However, few published studies have attempted to systematically evaluate the achievable DR potential of large interconnected electric power systems.

In [67] the shifting load potential is assessed for the German power system constrained by the consumers' acceptance and also limiting the disconnection rates (which in practice means that the applications must be reconnected after a predefined time). Therefore, the authors of [67] considered the social acceptance of DR (specifically for the residential and commercial sectors). Ref. [41] highlights that "human nature is a further issue which compounds the problem of market design for demand response. While large generators typically exhibit economically rational behaviour through their profit maximising objective, smaller customers do not show the same rationality in their consumption decisions".

The authors of [92] highlight that the effective implementation of DSM strategies (e.g. DR measures) strongly depends on social acceptance. Ref. [70] considered the calculation of an "approximated social potential". Due to the set of complex features associated to the estimation of the achievable DR potential, it is probable that the author of [70] used the term 'approximated' in his definition because of the highly diverse, multifaceted and complex nature of the achievable DR assessment.

\section{A New Conceptual Framework to estimate DR potentials}

There are two main methods for assessing the flexible load potential namely aggregated and decomposition methods [71]. For the aggregated approach, market mechanisms are used to assess changes in demand in accordance with market conditions (e.g. electricity price change) [71]. For the methodology proposed in this paper, the potential of flexible loads is assessed by broadly splitting up the potential candidates into a flexible and an inflexible component for each category (i.e. using the decomposition method) such as proposed by [63] . Then, for each sector, the decomposition of electricity consumption into several process/appliances is realized and individually assessed such as suggested and applied by several works in the literature [71]. Load flexibility may be also assessed in terms of the amount of electricity (GWh), power (GW), time, type (e.g. load shedding and load shifting) as well as cost [92]. Depending on the variables used in the analysis, different DR potentials may be assessed (see Fig. 5).

Ref. [10] points out that because of the different categories of DR potentials and considering the diverse set of constraints evolved, the DR potentials need to be treated separately. Therefore, after conducting a systematic literature review, the need for a framework which would systematically support the estimation of each DR potential was identified as the research gap. In addition, different methodological approaches have been considered and literature mostly focuses on the estimation of country-specific potentials and in a very limited extent research in the topic has considered the stepby-step procedure to assess each category of DR potential. Consequently, based on the prior knowledge obtained by the conducted systematic review analysis an improved conceptual framework is proposed. The general overview of the methodological approach for assessing the different categories of DR potential is illustrated in Fig. 5. 


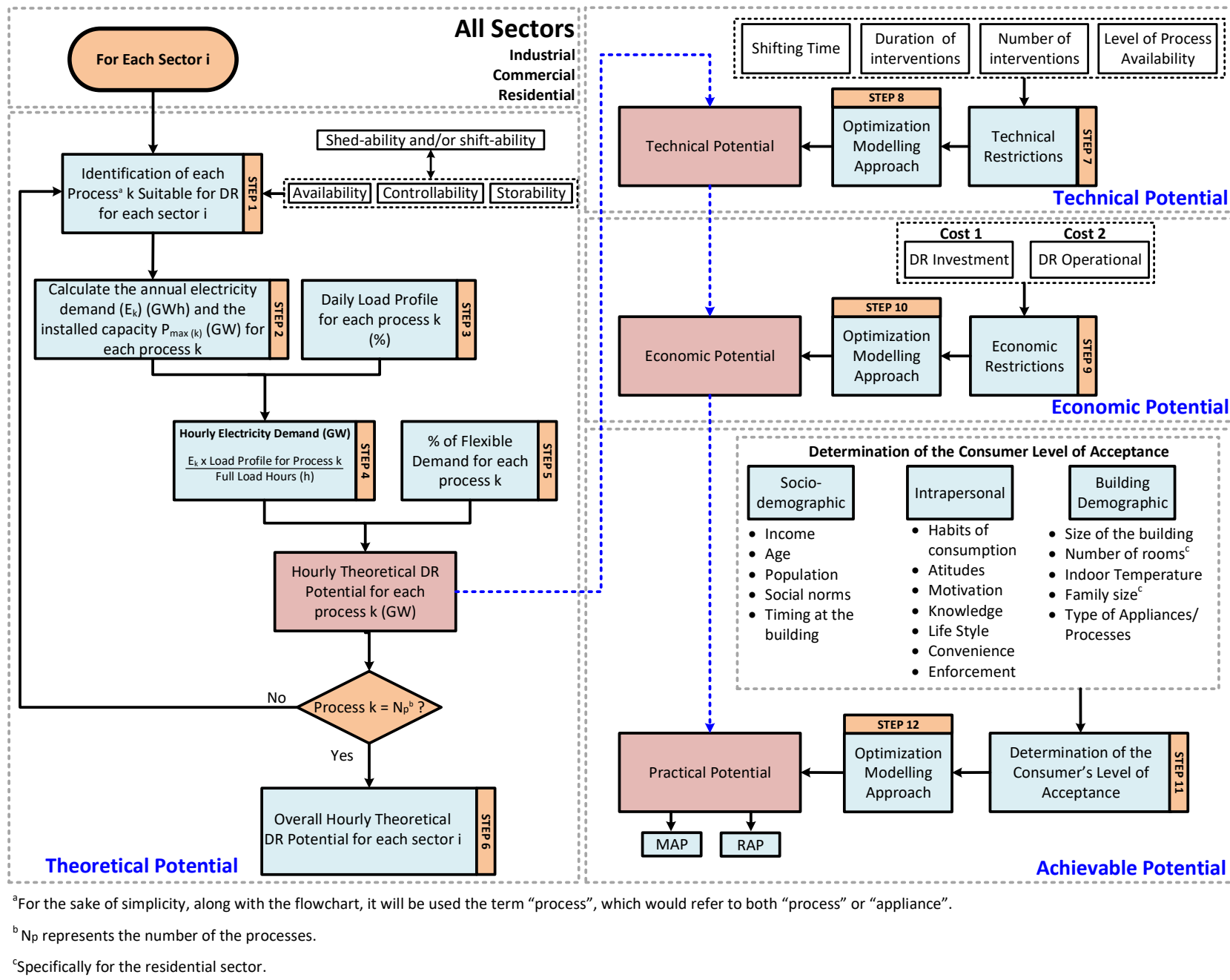

Fig. 5. Key steps of the proposed framework for the estimation of each DR potential category.

The following subsections will present the proposed twelve-step methodology to identify the different categories of DR potentials illustrated in Fig. 5. The methodology is divided into the four main categories for DR potentials (i.e. Theoretical, Technical, Economic and Achievable). The theoretical DR potential is addressed in the subsection 5.1 following the first six steps (step 1 to step 6). The technical DR potential derives from the theoretical DR potential by applying step 7 and step 8 as described in subsection 5.2. Departing from the technical DR potential, the economic DR potential is discussed in subsection 5.3. This estimation requires an assessment of the costs of implementing DR as presented in step 9 and step 10. Finally, subsection 5.4 addresses the achievable DR potential through the last two steps (step 11 and step 12) for which the consumers level of acceptance is considered.

\subsection{Theoretical DR Potential: Step 1 to Step 6}

This section aims to present the step-by-step procedure for the estimation of the theoretical DR potential.

\section{Step 1: Identification for each process/appliance suitable for DR for each sector}

The starting point of the analysis comprises the identification of the potential flexible loads (processes and/or appliances) suitable for load shedding and/or load shifting for each sector ${ }^{3}$ desired (Step 1). This identification has been traditionally undertaken through a qualitative assessment of technologies [53]. It is worth mentioning that this identification would require different criteria evaluation for each sector (i.e. residential, commercial and industrial). The shed-ability and/or shift-ability characteristics of each process/appliance would be taken into account which is also interconnected with the following technologies characteristics: availability, storability and controllability [49].

Table 4 presents the main processes/appliances with some degree of DR potential, but are not limited to only these applications and would vary between countries and sectors. To give a well-known example for the sake of clarity, for the residential and commercial sector, the controllability versus non-controllability and storability versus non-storability of the service might be taken into account for the selection of the suitable processes/appliances for DR. Therefore, the

\footnotetext{
${ }^{3}$ It is worth mentioning that according to [10], traditionally "for processes with very high utilization rates - as they are found in energy-intensive industries - only load shedding without previous or subsequent balancing can be implemented. In residential and commercial sector, typically both load shifting and shedding can be realized".
} 
suggested criteria used along with this work to select the suitable processes/ appliances for DR is whether it is storable and automatically controlled. This can be seen in the case of the refrigerator (for the residential sector) which has a storability characteristic and therefore could be considered suitable to contribute to DR. Similarly, the washing equipment (e.g. washing machine, dishwasher and tumble dryers) would be suitable because of its controllability characteristic. The independence between processes might be added to the selection of suitable DR processes for the industrial sector although this is not considered a trivial task [71]. For this reason, most of the previous studies do not take into account this last aspect in the selection process.

Table 4: Representation of the main processes with some degree of DR potential $[60,84]$.

\begin{tabular}{lll}
\hline \multicolumn{1}{c}{ Residential } & \multicolumn{1}{c}{ Industrial } & \multicolumn{1}{c}{ Commercial } \\
\hline Air-conditioning & Paper machines & Air-conditioning \\
Washing machines & Non-metallic minerals & Ventilation \\
Tumble Dryers & Non-ferrous metals & Refrigeration \\
Dishwashers & Chemical and petrochemical & Storage water heater \\
Water heaters & Iron \& steel & Storage heater \\
Refrigerators and freezers & Wood products & Wastewater treatment \\
Heating systems and electric boilers & Air Separation & Pumps in the water supply \\
& Cement Mills & Cold storages \\
& Wastepaper processing & \\
\hline
\end{tabular}

\section{Step 2: Quantification of Flexible Loads: Calculation of the Annual Electricity Demand and the Maximum} Installed Capacity

The estimation of the annual electricity demand and the maximum installed capacity for each process/appliance $\mathrm{k}$ over each sector i should be calculated in this step. However, this calculation strongly varies among sectors. This aspect can be mostly explained by both the technical differences across each process/appliance and also considering the scarcity and sparsity of available data. For this reason, for the industrial and commercial sectors, a top-down approach is traditionally considered in the literature whereas a bottom-up approach is usually considered for the estimation of the annual electricity demand for the residential sector. Therefore, these assumptions are taken into account in this step. A summary of the equations used to the quantification of the flexible load potential for each sector is mostly driven based on the assumptions ${ }^{4}$ of [60] and is provided in Table 5.

The quantification of the DR potential for energy-intensive industries is based on the specific electricity consumption and production capacities. As for the commercial sector, due to data scarcity, the combination between each individual process and its share is frequently used to categorize the overall electricity consumption. Therefore, the calculation of the annual electricity consumption is based on the average annual consumption.

For the residential sector, the specific electricity consumption might be calculated considering the technical characteristics of each appliance and therefore it would vary across different appliances and regions. Detailed calculation of the specific electricity consumption of each appliance can be found on [60]. To give a well-known example for the sake of clarity, the duration and frequency of use for washing equipment could also be taken into consideration for estimating its annual electricity consumption. Average values can also be used based on equipment data sheets. It is worth mentioning that the overall potential of the flexible demands mainly for the residential sector is highly dependent on the appliances characteristics (i.e. type, power, efficiency and rate of each equipment) and also on the pattern of consumption of these appliances which are affected mostly by the per capita income and the willingness to use more efficient technologies [93].

Table 5: Summary of the equations used to the quantification of the flexible load potential for each sector.

\begin{tabular}{|c|c|c|c|}
\hline Sector & \multicolumn{2}{|l|}{$\begin{array}{r}\text { Equation } \\
\end{array}$} & Definition \\
\hline \multirow[b]{2}{*}{ Industrial } & $E_{\text {year_ind }}^{k}=A_{\text {year }}^{k} \cdot E_{\text {spec }}^{k} \cdot s_{\text {util }}^{k}$ & (1) & Annual electricity consumption (GWh) \\
\hline & $P_{\text {max_ind }_{-}^{k}}^{k}=\frac{E_{\text {year_ind }}^{k}}{N_{h_{-} \text {year }} \cdot\left(1-f_{\text {rev }}^{k}\right) \cdot s_{\text {util }}^{k}}$ & (2) & Maximum Installed capacity (GW) \\
\hline \multirow[b]{2}{*}{ Commercial } & $E_{\text {year_com }}^{k}=E_{\text {com }}^{k} \cdot s_{\text {com }}^{k}$ & (3) & Annual electricity consumption (GWh) \\
\hline & $P_{\max \_c o m^{k}}^{k}=\frac{E_{y e a r_{-} c o m}^{k}}{n_{F L H}^{k}}$ & (4) & Maximum Installed capacity $(\mathrm{GW})$ \\
\hline \multirow{2}{*}{ Residential } & $E_{\text {year_res }}^{k}=n_{\text {house }} \cdot f_{\text {eq }}^{k} \cdot E_{\text {unit }}^{k}$ & $(5)$ & Annual electricity consumption (GWh) \\
\hline & $P_{\text {max_res }}^{k}=n_{\text {house }} \cdot f_{\text {eq }}^{k} \cdot P_{\text {unit }}^{k}$ & (6) & Maximum Installed capacity (GW) \\
\hline
\end{tabular}

\footnotetext{
${ }^{4}$ The author of [60] also includes equations for estimating the overall potential of load reduction and load increase for each hour. We highlight that these equations could also be included in the framework proposed in this paper. In this case, the calculation of the potential of load reduction and increase should be performed after Step 2 using the set of equations presented in [60].
} 


\section{Step 3: Daily Load Profile for each process}

In order to calculate the Hourly Electricity Demand in the next step (i.e. Step 4), and therefore, to account for the temporal availability of DR potential, the typical load profiles for each process/appliance should be estimated by using metered data or considering the typical profile patterns according to the available literature [60]. The selection of the representative load curves on a daily, weekly and/or seasonal base is of particular importance and it would be considered if there is available data [60]. Traditionally, energy-intensive industries run at full capacity over the entire year, due to both the huge heterogeneity of processes and because of its high utilization rates. Therefore, a constant load profile over the entire year is usually considered in the literature such as in [10] and [63].

The load profile is dependent on a set of diverse variables and therefore it can be considered dynamic, non-linear and time-varying [41]. For this reason, the future ${ }^{5}$ projections are considered by literature highly uncertain. Detailed end-use load profiles for each customer segment considering both a reasonable sample and length of time would also potentialize the future estimations of DR potentials. Traditionally, the load profiles for all DR processes/appliances remain unchanged for the estimation of the flexibility potential in future years such as considered in such as in [10] and [63].

\section{Step 4: Hourly Electricity Demand}

At this step, the hour electricity demand should be calculated. Combining the annual electricity demand (Step 2) with the load usage pattern (Step 3) and also taking into account the full load hours, the hourly electricity demand (Step 4) can be calculated for each process $\mathrm{k}$ according to Eq. (7) [63].

$$
E_{\text {hourly }}^{k}=\frac{E_{\text {year }}^{k} \cdot D_{\text {profile }}^{k}}{n_{F L H}^{k}}(G W)
$$

\section{Step 5: Percentage of Flexible Demand for Each Process/Appliance}

For each process/appliance k, the percentage of flexible demand needs to be estimated to further calculate the Hourly Theoretical DR Potential for each process/appliance k. The share of flexible demand for each process/appliance would strongly differ between each other.

\section{Step 6: Overall Hourly Theoretical DR Potential for Each Sector}

For each sector i and year $\mathrm{y}$, the sum for all processes $\mathrm{k}$ which contribute to the DR potential gives the overall hourly theoretical DR potential which can be calculated by using Eq. (8). Therefore, the sum of all suitable DR processes/appliances comprises the total DR potential of a power system [63].

$$
E_{\text {hourly }(i)}^{k}=\sum_{k=1}^{N}\left(E_{\text {hourly }}^{k} \cdot F D^{k}\right) \forall k, y(G W h)
$$

\subsection{Technical DR Potential: Step 7 to Step 8}

The following steps (Step 7 and 8) allows the estimation of the technical DR potential.

\section{Step 7: Technical Restrictions}

This step comprises the inclusion of a set of technical restrictions in order to estimate the Technical DR Potential. The shifting time, duration and number of DR interventions can be considered the most important technical restrictions to be taken into account in addition to the level of availability of each process/appliance.

\section{Step 8: Optimization Modelling Approach}

The use of an optimization modeling approach is usually ${ }^{6}$ considered to support the assessment of the technical DR potential of the overall electricity system. Within the optimization model, the technical restrictions (Step 7) would constrain the planning model. Different optimization modeling approaches (e.g. linear programming or stochastic programming) can be used, but the detailed description of each optimization approach is out of the scope of this research paper.

\footnotetext{
5 The extrapolation of the flexibility potential for each process/appliance is necessary when the potential of flexible loads is quantified for future years (y). This stage would require a broad literature review and in general it is based on available statistics of recent technology developments. To give a well-known example for the sake of clarity, for the residential sector, the increasing intensity of use of appliances should be used in the extrapolation of data [60]. Different shares of flexible demand would also be taken into account when extrapolation for future years is considered since it could change over years. This happens because of two main reasons: the electricity consumption would increase and the future DR potential would also change according to the deployment of the technologies [63].

${ }^{6}$ The use of simulation models is still possible such as considered by [71].
} 


\subsection{Economic DR Potential: Step 9 to Step 10}

The economic DR potential can be further assessed by the use of Steps 9 and Step 10.

\section{Step 9: Economic Restrictions}

The economic restrictions need to be taken into account in order to assess the economic DR potential. Here, two different costs are traditionally associated with the DR. The investment costs (i.e. associated with the ICT necessary to automatized adjustment control, smart metering systems and program design) and the operational costs (i.e. variable and annual fixed costs) [48]. The operational costs might also include marketing and other administrative maintenance costs [94].

\section{Step 10: Optimization Modelling Approach}

See Step 8. For this case, the economic restrictions (Step 9) would be also used to constrain the optimization model, which would support the final assessment of the economic DR potential of the electricity system.

\subsection{Achievable DR Potential: Step 11 to Step 12}

Finally, the following steps (Step 11 and Step 12) support the estimation of the achievable DR potential.

\section{Step 11: Determination of the Consumers' Level of Acceptance}

The estimation of the achievable DR potential comprises a difficult task since it depends on the evaluation of a set of qualitative variables (e.g. informational, legal, technical, organization and financial barriers in addition to the lack of consumers' experience [59]) such as illustrated in Fig. 5. The authors of [47] agree with this and also point out that "the determination of the market potential for a certain technology imposes challenges in setting a valid scientific methodology". The main barriers include the lack of consumers' acceptance, lack of enforcement, market structure and information gaps [25]. The end-user behavior plays a major role in the effective implementation of DR measures [28]. Ref. [67] point out that the maximum shift duration, for example, for each process/appliance mostly depends on the customers' acceptance. Results from earlier studies such as [95] and [96] demonstrate that consumers' responses to prices might be asymmetric, increasing considerably their consumption on off-peak periods but with limited reductions on the electricity consumption during on-peak times. Ref. [85] assessed the flexibility potential of five household appliances based on real measured data for a large pilot test in Belgium and reported that the flexibility potential of household smart appliances is highly asymmetric. Therefore, the willingness to accept load interventions (i.e. load shedding and/or load shifting) by end-users may be evaluated using both qualitative and quantitative analysis [49]. The effective DR implementation (i.e. achievable DR potential), is thus lower than the economic DR potential since it depends on the level of consumers' acceptance.

\section{Step 12: Optimization Modelling Approach}

See Step 8. For this case, the restrictions from Step 11 would be also considered to constrain the optimization model, in order to properly account for the flexibility potential of the consumers and reach a final assessment of the achievable DR potential of the electricity system.

\section{Discussion of the Findings}

This section will attempt to discuss the main findings which emerged from the literature review. This study found that different methodologies have been used to the evaluation of the different categories of DR potentials. Ref. [97] reviewed the DR experience in Europe and highlighted that "studies on the economic and technical potential of DR vary significantly in methods, sample sizes and results". In [63] an overview with a focus on DR potentials is addressed. The authors of [64] point out that in the review analysis of DR potentials undertaken by [63] "the authors remark significant variations in the considered studies, which may be explained by a different scoping and assessment method of the analyzed demand response potential". Therefore, previous studies vary strongly in their findings concerning DR potentials.

According to [72] the "lack of experience with demand response has necessitated the employment of numerous assumptions in the modeling approaches adopted. As a consequence, it can be argued that the estimations of the benefit of demand response are dependent on these assumptions and an accurate evaluation has yet to be achieved". For this reason, the DR potential estimation varies between studies even considering the same power system such as better demonstrated by [63]. In this context, Ref. [41] also points out that because of both the lack of experience and understanding of the complex nature of DR, superficial results have been obtained by great part of works published in the literature due to its simplistic models and consequently several analyses might be oversimplified with unrealistic results and which do not represent correctly the reality. Ref. [98] points out that these differences occur mostly because of the different methods used for the estimation of DR potentials. To give a well-known example for the sake of clarity, some authors estimate the average potential whereas others use an hourly estimation of DR potential.

Ref. [63] analyzed six different projections which estimated the DR potential for Germany and pointed out that the most of previously published works consider "only the maximum potential and do not consider temporal availability in detail". However, the DR potential is strongly dependent on temporal availability (e.g. hour of the day), indoor temperature and season, for instance [63]. The technical DR potential for Germany was recently addressed by the authors 
of [63]. The maximum technical DR potential considering both load shedding and load shifting estimated by [63] was nearly $25 \mathrm{GW}$ (using data for the year 2013). However, the authors of [63] point out that this potential will never be available because the electricity consumption varies for each hour (i.e. daily, weekly and season for instance). Therefore, the temporal availability [99] and the spatial distribution [10] of the flexible loads are of particular importance. The temporal availability has been traditionally taken into account through the identification of typical daily load profiles. Due to the lack of measurements, typical demand load patterns are traditionally considered based on data from the available literature. Flexible loads for commercial and industrial sectors have been traditionally estimated based on their annual electricity consumption. Ref. [63] also addressed the question if the technical DR potential is available when needed (i.e. mostly during on-peak times) and concluded that the maximum DR potential for the power system evaluated occurs during off-peak times (i.e. only a small share of the DR potential is available when the power system mostly needs). The maximum hourly potential provides a flexible demand slightly lower than $14 \mathrm{GW}$ (which is considerably lower than the maximum available capacity of about $25 \mathrm{GW}$ ) for the power system evaluated in [63].

Based on the literature review it became obvious that the classification of the different categories of demand response potentials are far from being consensual and the methods for their estimation are not yet fully established. The framework presented in Fig. 5 allowed to provide guidelines for bringing consensus to the DR potential classification and solving the estimation problem, supported on a solid scientific background derived from the literature review. Given the complex nature of the estimation problem and the heterogeneity of the sector and power systems, just a small sample of numerical approaches and equations are proposed but the user-friendly and step-by-step nature of the theoretical framework is deemed to be of high benefit for the power systems community and decision makers.

\section{Conclusion \& Outlook}

This paper addressed two central issues and the findings make several contributions to the current literature. The strengths of this study include the in-depth systematic review analysis regarding the different categories of DR potentials, which allowed not only to reach some consensus on the definition of DR categories but also on the main steps to be followed for its estimation.

Firstly, it was demonstrated - through an in-depth systematic review analysis - that there is a lack of understanding of the different categories of DR potentials, which sometimes have been unduly used by the available literature. The DR potentials were standardized into four main categories: Theoretical, Technical, Economic and Achievable. Findings of this study also reveal that there is a general agreement in the literature regarding the definition of the theoretical and economic DR potentials. However, significant differences can be identified when distinguishing the so-called technical and achievable DR potentials, which has been defined in different ways within the literature. Therefore, the unification of these different classifications was proposed in order to avoid misleading research on this topic. This would simultaneously contribute to overcoming the above-mentioned barriers, by making easier future reviewing pathways, for example. The research presented here also confirmed that different terms have been used to refer to "DR potentials", which includes mostly: (1) Demand Response Potential, (2) Demand-side Flexibility, (3) Flexible Demand Potential, (4) Flexible Load Potential and (5) Load Flexibility Potential, which oftentimes has been used interchangeably in the literature.

Secondly, a well-founded and user-friendly framework - which would strongly help the quantification of the DR flexibility across different sectors and applications - is proposed. In contrast to other review papers which addressed different DR issues, the scientific contribution of this research relies mostly on the novel theoretical framework based on an integrated approach for the determination of the different categories of DR potentials.

The DR potential estimation may somewhat vary between studies for the same power system and this can be mostly explained by the fact that some works consider the theoretical potential, which represents an upper bound for the other potentials (i.e. technical, economic and achievable). Overall, the studies reviewed here clearly indicate the importance of the temporal availability of DR applications which has been neglected by part of the published works. The findings also raised important theoretical issues that have a bearing on the quantification of the DR potential in the long-term. The estimation of the future DR potentials is particularly valuable in order to contribute to a sustainable future. The evidence reviewed here seems to suggest a pertinent role for the use of effective approaches for the detailed estimation of end-use load profiles for each customer segment considering both a reasonable sample and length of time which would potentialize the future estimations of all categories of DR potentials. Also, the determination of the technical suitability and the load flexibility potential for each end-use-level and customer segment is considered to be essential to accurately reflect in realistic DR potentials future estimations.

To summarize, the holistic assessment of the potential contribution of DR needs to surpass a set of barriers including technical and non-technical ones. Regulatory barriers can be considered one of the most important aspects to be addressed in order to improve the deployment of DR and also to enable customer participation in DR initiatives. The non-technical barriers for the adoption of DR mechanisms would also be taken into account in order to assess the achievable DR potential, for example. Finally, it can be concluded that although many advances have been observed over the past years, primarily in developing countries, many challenges and barriers (e.g. technical, market and behavioral) associated with the DR deployment still exists and appears as potential challenges for the deployment and dissemination of DR strategies. The effectiveness of DR programs is also strongly dependent on government policies and regulations that should have reliable and long-term support. Therefore, the outcomes of our literature review also lead to the conclusion that the evaluation of potential benefits of DR measures should be addressed in a holistic manner, considering the external benefits for the entire energy system (e.g. using a portfolio analysis) which would potentialize the cost-effectiveness of DR and become a more attractive demand-side option. 
A few limitations need to be noted regarding the present study. Firstly, it is worth mentioning that the generalizability of much published research on this issue is problematic and it is not considered a trivial task since each power system has its particular characteristics. Secondly, more research on this topic needs to be undertaken, addressing the trade-offs of each methodology that had been considered to evaluate the different categories of DR potentials. However, despite these limitations, we highlight the potential of replicability of the methodology proposed in this paper to evaluate the different categories of DR potentials across both different customer segments and power systems.

\section{Acknowledgments}

This work is supported by the National Council for Scientific and Technological Development (CNPq), Brazil. This work has been supported by FCT - Fundação para a Ciência e Tecnologia (Portugal) within the Project Scope: UID/CEC/00319/2019 and the ERDF - European Regional Development Fund through the Operational Programme for Competitiveness and Internationalisation COMPETE 2020 Programme, and by National Funds through FCT, within project SAICTPAC/0004/2015 POCI/01/0145/FEDER/016434.

\section{References}

[1] EPE. Plano Decenal de Expansão de Energia 2026. Ministério Minas e Energ 2017:264. http://www.epe.gov.br/pt/publicacoes-dados-abertos/publicacoes/plano-decenal-de-expansao-de-energia-pde (accessed February 10, 2018).

[2] Blanco H, Faaij A. A review at the role of storage in energy systems with a focus on Power to Gas and long-term storage. Renew Sustain Energy Rev 2018;81:1049-86. doi:10.1016/j.rser.2017.07.062.

[3] Council NRD, Alliance C-UEE, Center SGNDI. DSM Program Procedures Manual Volume I-Industrial Energy Efficiency Program. 2008.

[4] Hu Z, Han X, Wen Q. Integrated Resource Strategic Planning and Power Demand-Side Management. Power Syst $2013 ; 80$. doi:10.1007/978-3-642-37084-7.

[5] Welsch M. Enhancing the Treatment of Systems Integration in Long-term Energy Models. KTH Royal Institute of Technology, 2013.

[6] Zhang S, Jiao Y, Chen W. Demand-side management (DSM) in the context of China's on-going power sector reform. Energy Policy 2017;100:1-8. doi:https://doi.org/10.1016/j.enpol.2016.09.057.

[7] Ming Z, Song X, Mingjuan M, Lingyun L, Min C, Yuejin W. Historical review of demand side management in China: Management content, operation mode, results assessment and relative incentives. Renew Sustain Energy Rev 2013;25:470 82. doi:https://doi.org/10.1016/j.rser.2013.05.020.

[8] Meyabadi AF, Deihimi MH. A review of demand-side management : Reconsidering theoretical framework. Renew Sustain Energy Rev 2017;80:367-79. doi:10.1016/j.rser.2017.05.207.

[9] Baetens R, Dierckxsens C, Mijlemans L, Joseph P, Krisper U. Requirements for DR \& DG participation in aFRR Markets. 2016.

[10] Gils HC. Assessment of the theoretical demand response potential in Europe. Energy 2014;67:1-18. doi:10.1016/J.ENERGY.2014.02.019.

[11] Karunanithi K, Saravanan S, Prabakar BR, Kannan S, Thangaraj C. Integration of Demand and Supply Side Management strategies in Generation Expansion Planning. Renew Sustain Energy Rev 2017;73:966-82. doi:10.1016/J.RSER.2017.01.017.

[12] Gelazanskas L, Gamage KAA. Demand side management in smart grid: A review and proposals for future direction. Sustain Cities Soc 2014;11:22-30. doi:10.1016/j.scs.2013.11.001.

[13] Bian Y, Wang H, Wyman-Pain H, Gu C, Li F. Frequency Response in the GB Power System from Responsive CHPs. Energy Procedia 2017;105:2302-9. doi:https://doi.org/10.1016/j.egypro.2017.03.664.

[14] Brijs T, De Jonghe C, Hobbs BF, Belmans R. Interactions between the design of short-term electricity markets in the CWE region and power system flexibility. Appl Energy 2017;195:36-51. doi:https://doi.org/10.1016/j.apenergy.2017.03.026.

[15] Van Stiphout A, De Vos K, Deconinck G. The Impact of Operating Reserves on Investment Planning of Renewable Power Systems. IEEE Trans Power Syst 2017;32:378-88. doi:10.1109/TPWRS.2016.2565058.

[16] Mcclurg JC. Reduction of reserve margin with increasing wind penetration: a quantitative first-principles analysis. University of Iowa, 2012.

[17] Zhang N, Hu Z, Shen B, Dang S, Zhang J, Zhou Y. A source-grid-load coordinated power planning model considering the integration of wind power generation. Appl Energy 2016;168:13-24. doi:10.1016/j.apenergy.2016.01.086.

[18] Jordehi AR. Optimisation of demand response in electric power systems, a review 2019. doi:10.1016/j.rser.2018.12.054.

[19] Fotouhi Ghazvini MA, Soares J, Abrishambaf O, Castro R, Vale Z. Demand response implementation in smart households. Energy Build 2017;143:129-48. doi:10.1016/j.enbuild.2017.03.020.

[20] Paterakis NG, Erdinç O, Catalão JPS. An overview of Demand Response: Key-elements and international experience. Renew Sustain Energy Rev 2017;69:871-91. doi:10.1016/j.rser.2016.11.167.

[21] Eid C, Koliou E, Valles M, Reneses J, Hakvoort R. Time-based pricing and electricity demand response: Existing barriers and next steps. Util Policy 2016;40:15-25. doi:10.1016/j.jup.2016.04.001.

[22] IEA. WEO 2017. IEA World Energy Outlook 2017. doi:10.1787/weo-2017-en.

[23] Rathore C, Roy R, Paterakis NG, Erdinç O, Catalão JPS, Prod G, et al. Impact of wind uncertainty, plug-in-electric vehicles and demand response program on transmission network expansion planning. Int J Electr Power Energy Syst 2016;75:59-73. doi:10.1016/j.ijepes.2015.07.040.

[24] Satchwell A, Hledik R. Analytical frameworks to incorporate demand response in long-term resource planning. Util Policy 2014;28:73-81. doi:10.1016/j.jup.2013.12.003.

[25] Klobasa M. Analysis of demand response and wind integration in Germany's electricity market. IET Renew Power Gener 2010;4:55-63. doi:10.1049/iet-rpg.2008.0086.

[26] Smith K, Managan K. Energy Efficiency and Demand Response: Working Together in an Integrated Approach to Managing Energy. Inst Fir Build Effic 2012:8. 
[27] Nolan S, O’Malley M. Challenges and barriers to demand response deployment and evaluation. Appl Energy 2015;152:1-10. doi:10.1016/j.apenergy.2015.04.083.

28] Hussain M, Gao Y. A review of demand response in an efficient smart grid environment. Electr J 2018;31:55-63. doi:10.1016/J.TEJ.2018.06.003.

[29] Marañón-Ledesma H, Tomasgard A. Long-Term Electricity Investments Accounting for Demand and Supply Side Flexibility. 2019.

[30] Verzijlbergh RA, De Vries LJ, Dijkema GPJ, Herder PM. Institutional challenges caused by the integration of renewable energy sources in the European electricity sector. Renew Sustain Energy Rev 2017;75:660-7. doi:10.1016/j.rser.2016.11.039.

[31] Cui W, Li L. A game-theoretic approach to optimize the Time-of-Use pricing considering customer behaviors 2018. doi:10.1016/j.ijpe.2018.04.022.

[32] Avancini DB, Rodrigues JJPC, Martins SGB, Rab RAL, Al-Muhtadi J, Solic P. Energy meters evolution in smart grids: A review 2019. doi:10.1016/j.jclepro.2019.01.229.

[33] Ren G, Liu J, Wan J, Guo Y, Yu D. Overview of wind power intermittency: Impacts, measurements, and mitigation solutions. Appl Energy 2017;204:47-65. doi:10.1016/j.apenergy.2017.06.098.

[34] Anderson CL, Cardell JB. A Vision for Co-optimized T \& D System Interaction with Renewables and Demand Response. Proc. 50th Hawaii Int. Conf. Syst. Sci., 2017, p. 2975-82.

[35] Torstensson D, Wallin F. Potential and Barriers for Demand Response at Household Customers. Energy Procedia 2015;75:1189-96. doi:https://doi.org/10.1016/j.egypro.2015.07.570.

[36] Shariatzadeh F, Mandal P, Srivastava AK. Demand response for sustainable energy systems: A review, application and implementation strategy. Renew Sustain Energy Rev 2015;45:343-50. doi:10.1016/J.RSER.2015.01.062.

[37] Saunders M, Lewis P, Thornhill A. Research Methods for Business Students. Seventh ed. England: 2016. doi:10.1007/s13398014-0173-7.2.

[38] Mardani A, Zavadskas EK, Khalifah Z, Zakuan N, Jusoh A, Nor KM, et al. A review of multi-criteria decision-making applications to solve energy management problems: Two decades from 1995 to 2015. Renew Sustain Energy Rev 2016:1-44. doi:10.1016/j.rser.2016.12.053.

[39] Haddaway NR, Macura B. The role of reporting standards in producing robust literature reviews. Nat Clim Chang 2018;8:4447. doi:10.1038/s41558-018-0180-3.

[40] Garcez CAG. What do we know about the study of distributed generation policies and regulations in the Americas? A systematic review of literature. Renew Sustain Energy Rev 2016:0-1. doi:10.1016/j.rser.2016.11.129.

[41] O'Connell N, Pinson P, Madsen H, O'Malley M. Benefits and challenges of electrical demand response: A critical review. Renew Sustain Energy Rev 2014;39:686-99. doi:10.1016/J.RSER.2014.07.098.

[42] Boßmann T, Eser EJ. Model-based assessment of demand-response measures-A comprehensive literature review. Renew Sustain Energy Rev 2016;57:1637-56. doi:10.1016/J.RSER.2015.12.031.

[43] Imani MH, Ghadi MJ, Ghavidel S, Li L. Demand Response Modeling in Microgrid Operation: a Review and Application for Incentive-Based and Time-Based Programs. Renew Sustain Energy Rev 2018;94:486-99. doi:https://doi.org/10.1016/j.rser.2018.06.017.

[44] Yan X, Ozturk Y, Hu Z, Song Y. A review on price-driven residential demand response. Renew Sustain Energy Rev 2018;96:411-9. doi:10.1016/J.RSER.2018.08.003.

[45] Zhou K, Yang S. Demand side management in China: The context of China's power industry reform. Renew Sustain Energy Rev 2015;47:954-65. doi:https://doi.org/10.1016/j.rser.2015.03.036.

[46] Khan AR, Mahmood A, Safdar A, Khan ZA, Khan NA. Load forecasting, dynamic pricing and DSM in smart grid: A review. Renew Sustain Energy Rev 2016;54:1311-22. doi:https://doi.org/10.1016/j.rser.2015.10.117.

[47] Kondziella H, Bruckner T. Flexibility requirements of renewable energy based electricity systems - a review of research results and methodologies. Renew Sustain Energy Rev 2016;53:10-22. doi:10.1016/J.RSER.2015.07.199.

[48] Paulus M, Borggrefe F. The potential of demand-side management in energy-intensive industries for electricity markets in Germany. Appl Energy 2011;88:432-41. doi:10.1016/J.APENERGY.2010.03.017.

[49] Aduda KO, Labeodan T, Zeiler W, Boxem G, Zhao Y. Demand side flexibility: Potentials and building performance implications. Sustain Cities Soc 2016;22:146-63. doi:10.1016/J.SCS.2016.02.011.

[50] Lopes RA, Chambel A, Neves J, Aelenei D, Martins J. A Literature Review of Methodologies Used to Assess the Energy Flexibility of Buildings. Energy Procedia 2016;91:1053-8. doi:10.1016/J.EGYPRO.2016.06.274.

[51] Bode G, Behrendt S, Fütterer J, Müller D. Identification and utilization of flexibility in non-residential buildings. Energy Procedia 2017;122:997-1002. doi:10.1016/J.EGYPRO.2017.07.461.

[52] Rogers AP, Rasmussen BP. Opportunities for consumer-driven load shifting in commercial and industrial buildings. Sustain Energy, Grids Networks 2018;16:243-58. doi:10.1016/J.SEGAN.2018.08.004.

[53] Pechmann A, Shrouf F, Chonin M, Steenhusen N. Load-shifting potential at SMEs manufacturing sites: A methodology and case study. Renew Sustain Energy Rev 2017;78:431-8. doi:10.1016/J.RSER.2017.04.081.

[54] Yilmaz HÜ, Keles D, Chiodi A, Hartel R, Mikulić M. Analysis of the power-to-heat potential in the European energy system. Energy Strateg Rev 2018;20:6-19. doi:10.1016/j.esr.2017.12.009.

[55] Wu Y-K, Tang K-T. Frequency Support by Demand Response - Review and Analysis. Energy Procedia 2019;156:327-31. doi:https://doi.org/10.1016/j.egypro.2018.11.150.

[56] Energy USD of. Benefits of Demand Response in Electricity Markets and Recommendations for Achieving Them. 2006.

[57] Council NP and C. Sixth Northwest Conservation and Electric Power Plan. 2010.

[58] Siddiqui O. Assessment of achievable potential from energy efficiency and demand response programs in the US (20102030). Electr Power Res Institute, January 2009.

[59] Grein A, Pehnt M. Load management for refrigeration systems: Potentials and barriers. Energy Policy 2011;39:5598-608. doi:10.1016/J.ENPOL.2011.04.040.

[60] Gils HC. Balancing of Intermittent Renewable Power Generation by Demand Response and Thermal Energy Storage. University of Stuttgart, 2015.

[61] Yingqi M, Dr L, Eyre N, Darby S, Keay MM, Robinson D, et al. Assessment of Demand Response Market Potential and Benefits in Shanghai. Shangai: 2015. 
[62] AEG. State of Michigan Demand Response Potential Study - Technical Assessment. 2017.

[63] Müller T, Möst D. Demand Response Potential: Available when Needed? Energy Policy 2018;115:181-98. doi:10.1016/J.ENPOL.2017.12.025.

[64] Schoepf M, Weibelzahl M, Nowka L. The Impact of Substituting Production Technologies on the Economic Demand Response Potential in Industrial Processes. Energies 2018;11. doi:10.3390/en11092217.

[65] Grein A, Pehnt M. Load management for refrigeration systems: Potentials and barriers. Energy Policy 2011;39:5598-608. doi:10.1016/j.enpol.2011.04.040.

[66] Brouwer AS, van den Broek M, Zappa W, Turkenburg WC, Faaij A. Least-cost options for integrating intermittent renewables in low-carbon power systems. Appl Energy 2016;161:48-74. doi:10.1016/J.APENERGY.2015.09.090.

[67] Aryandoust A, Lilliestam J. The potential and usefulness of demand response to provide electricity system services. Appl Energy 2017;204:749-66. doi:10.1016/J.APENERGY.2017.07.034.

[68] Olkkonen V, Ekström J, Hast A, Syri S. Utilising demand response in the future Finnish energy system with increased shares of baseload nuclear power and variable renewable energy. Energy 2018;164:204-17. doi:10.1016/J.ENERGY.2018.08.210.

[69] Ikpe E, Torriti J. A means to an industrialisation end? Demand Side Management in Nigeria. Energy Policy 2018;115:20715. doi:10.1016/J.ENPOL.2018.01.011.

[70] Gils HC. Economic potential for future demand response in Germany - Modeling approach and case study. Appl Energy 2016;162:401-15. doi:10.1016/J.APENERGY.2015.10.083.

[71] Kwon PS, Østergaard P. Assessment and evaluation of flexible demand in a Danish future energy scenario. Appl Energy 2014;134:309-20. doi:10.1016/J.APENERGY.2014.08.044.

[72] Haider HT, See OH, Elmenreich W. A review of residential demand response of smart grid. Renew Sustain Energy Rev 2016;59:166-78. doi:10.1016/J.RSER.2016.01.016.

[73] Anjo J, Neves D, Silva C, Shivakumar A, Howells M. Modeling the long-term impact of demand response in energy planning: The Portuguese electric system case study. Energy 2018;165:456-68. doi:https://doi.org/10.1016/j.energy.2018.09.091.

[74] Gils HC, Simon S, Soria R. 100\% Renewable energy supply for Brazil-The role of sector coupling and regional development. Energies 2017;10. doi:10.3390/en10111859.

[75] Dantas GDA, de Castro NJ, Brandão R, Rosental R, Lafranque A, Castro NJ De, et al. Prospects for the Brazilian electricity sector in the 2030s: Scenarios and guidelines for its transformation. Renew Sustain Energy Rev 2017;68:997-1007. doi:10.1016/j.rser.2016.08.003.

[76] FGV. Distributed Energy Resources. 2016.

[77] Ma O, Alkadi N, Cappers P, Denholm P, Dudley J, Goli S, et al. Demand Response for Ancillary Services. IEEE Trans Smart Grid 2013;4:1988-95. doi:10.1109/TSG.2013.2258049.

[78] Álvarez Bel C, Ortega MA, Escrivá GE, Gabaldón Marín A. Technical and economical tools to assess customer demand response in the commercial sector. Energy Convers Manag 2009;50:2605-12. doi:10.1016/J.ENCONMAN.2009.06.002.

[79] LLC GEP. Midwest ISO Demand Response and Energy Efficiency Forecast. Walnut Creek, CA: 2010.

[80] Baek Y, Hadley SW, Uría-Martínez R, Oladosu G, Smith AM, Li F, et al. Eastern Interconnection Demand Response Potential. 2012.

[81] Olivieri SJ, Henze GP, Corbin CD, Brandemuehl MJ. Evaluation of commercial building demand response potential using optimal short-term curtailment of heating, ventilation, and air-conditioning loads. J Build Perform Simul 2014;7:100-18. doi:10.1080/19401493.2013.783118.

[82] Mathieu JL, Rasmussen TB, Sorensen M, Johannsson H, Andersson G. Technical resource potential of non-disruptive residential demand response in Denmark. 2014 IEEE PES Gen. Meet. | Conf. Expo., IEEE; 2014, p. 1-5. doi:10.1109/PESGM.2014.6938939.

[83] Tarragó OS. Demand Response Potential of Residential Load Equipments. Aalto University, 2014.

[84] Partners S. Demand Response: A study of its potential in Europe 2015:6. http://sia-partners.com/insights/demand-responsestudy-its-potential-europe (accessed November 7, 2018).

[85] D'hulst R, Labeeuw W, Beusen B, Claessens S, Deconinck G, Vanthournout K. Demand response flexibility and flexibility potential of residential smart appliances: Experiences from large pilot test in Belgium. Appl Energy 2015;155:79-90. doi:10.1016/j.apenergy.2015.05.101.

[86] Stötzer M, Hauer I, Richter M, Styczynski ZA. Potential of demand side integration to maximize use of renewable energy sources in Germany. Appl Energy 2015;146:344-52. doi:10.1016/J.APENERGY.2015.02.015.

[87] Kies A, Schyska UB, von Bremen L. The Demand Side Management Potential to Balance a Highly Renewable European Power System. Energies 2016;9. doi:10.3390/en9110955.

[88] Söder L, Lund PD, Koduvere H, Bolkesjø TF, Rosseb $\varnothing$ GH, Rosenlund-Soysal E, et al. A review of demand side flexibility potential in Northern Europe. Renew Sustain Energy Rev 2018;91:654-64. doi:https://doi.org/10.1016/j.rser.2018.03.104.

[89] Hayn M, Zander A, Fichtner W, Nickel S, Bertsch V. The impact of electricity tariffs on residential demand side flexibility: results of bottom-up load profile modeling. Energy Syst 2018;9:759-92. doi:10.1007/s12667-018-0278-8.

[90] Gnann T, Klingler A-L, Kühnbach M. The load shift potential of plug-in electric vehicles with different amounts of charging infrastructure. J Power Sources 2018;390:20-9. doi:10.1016/J.JPOWSOUR.2018.04.029.

[91] Dranka GG, Ferreira P. Planning for a renewable future in the Brazilian power system. Energy 2018;164:496-511. doi:10.1016/J.ENERGY.2018.08.164.

[92] Tronchin L, Manfren M, Nastasi B. Energy efficiency, demand side management and energy storage technologies - A critical analysis of possible paths of integration in the built environment. Renew Sustain Energy Rev 2018;95:341-53. doi:10.1016/J.RSER.2018.06.060.

[93] EPE. Demanda de Energia 2050. [Available from Http//WwwEpeGovBr/Estudos/Documents/DEA\%201314\%20Demanda\%20de\%20Energia\%202050Pdf] 2014:1-232 [acessed February, 19 th 2016].

[94] Sofana Reka S, Ramesh V. A Smart Survey on Demand Response Potential in Global Energy Market. Indian J Sci Technol 2015;8:474. doi:10.17485/ijst/2015/v8iS9/55411.

[95] Thorsnes P, Williams J, Lawson R. Consumer responses to time varying prices for electricity. Energy Policy 2012;49:55261. doi:10.1016/J.ENPOL.2012.06.062.

[96] Allcott H. Rethinking real-time electricity pricing. Resour Energy Econ 2011;33:820-42. 
825 [97] Torriti J, Hassan MG, Leach M. Demand response experience in Europe: Policies, programmes and implementation. Energy 2010;35:1575-83, doi:10.1016/J.ENERGY 2009.05.021.

[98] Söder L, Lund PD, Koduvere H, Bolkesjø TF, Rossebø GH, Rosenlund-Soysal E, et al. A review of demand side flexibility potential in Northern Europe. Renew Sustain Energy Rev 2018;91:654-64. doi:10.1016/J.RSER.2018.03.104.

[99] Grünewald P, Torriti J. Demand response from the non-domestic sector: Early UK experiences and future opportunities. Energy Policy 2013;61:423-9. doi:10.1016/J.ENPOL.2013.06.051. 